\title{
Controlled trial of bowel rest and nutritional support in the management of Crohn's disease
}

\author{
G R GREENBERG, C R FLEMING, $K$ N JEEJEEBHOY, I H ROSENBERG, \\ D SALES, AND W J TREMAINE
}

From the Departments of Medicine, University of Toronto, Toronto, Canada; Mayo Clinic, Rochester, MN; and University of Chicago, Chicago, IL, USA

SUMmary To define the role of bowel rest as an independent variable from nutritional support a prospective, randomised controlled trial was undertaken in 51 patients with active Crohn's disease unresponsive to other medical management. Nutritional support for 21 days was randomised to total parenteral nutrition and nil by mouth $(n=17)$, defined formula diet administered through a nasogastric tube $(n=19)$, or partial parenteral nutrition and oral food $(n=15)$. Nutrient input in the first two groups provided 40 non-protein $\mathrm{kcal} / \mathrm{kg}$ ideal body weight $/ \mathrm{d}$ and $1 \mathrm{~g} / \mathrm{kg} / \mathrm{d}$ protein respectively, while the third group received 15 non-protein $\mathrm{kcal} / \mathrm{kg} / \mathrm{d}$ and $0.3 \mathrm{~g} / \mathrm{kg} / \mathrm{d}$ protein intravenously and ate unrestricted food. Clinical remissions occurred in $71 \%$ of patients on parenteral nutrition, in $58 \%$ on the defined formula diet and in $60 \%$ on partial parenteral nutrition; the probability for each group of being in remission at one year, after successful therapy was $42 \%, 55 \%$, and $56 \%$ respectively. These differences were not significant. In patients with active Crohn's disease bowel rest was not a major factor in achieving a remission during nutritional support and did not influence outcome during one year's follow-up.

Patients with complicated Crohn's disease are often confronted with piece meal resections of the intestine or high dose corticosteroids (or both), with the knowledge that neither therapy assures lasting relief. An alternative which has found many advocates in recent years, is complete bowel rest and total parenteral nutrition (TPN). The proposed rationale for such treatment is that the absence of intraluminal nutrients - that is, bowel rest, minimises motor and transport functions of the diseased bowel and thus allows for a reduction in the inflammation. The use of standard hypotonic intravenous solutions with bowel rest in patients with Crohn's disease would result in rapid protein-calorie depletion. Total parenteral nutrition, however, by delivering adequate calories and other essential nutrients offers the advantage of maintaining or improving the nutritional state, that could also contribute to patient recovery.

Address for correspondence: Dr G R Greenberg, Medical Sciences Bldg. \#6356, University of Toronto, Ontario, Toronto, Ontario, Canada, M5S 1A8. Received for publication 11 March 1988.
Several studies on the use of TPN and bowel rest in Crohn's disease have reported favourable results ${ }^{1-7}$ but most involved small numbers of patients or lacked controls. Moreover, the mechanisms by which such therapy might contribute to the improvement in patients with Crohn's disease is unknown. The large caloric loads and weight gain may not be critical as comparable success in inducing remissions has been observed while maintaining positive nitrogen balance in the absence of an exogenous source of calories. ${ }^{8}$ Alternatively, the role of complete bowel rest has recently been questioned in a small but controlled study by Lochs $e^{2}$ al $^{9}$ where TPN with oral food was as efficacious in reducing the activity of Crohn's disease as TPN and nothing by mouth. Two prospective controlled trials ${ }^{11}$ have further indicated that elemental diets, which provide only partial bowel rest, achieves a remission rate in active Crohn's disease comparable with that of daily administration of prednisolone, although in each study the patient population receiving prednisolone had not pre- 
viously been refractory to drug therapy. Should comparable clinical and nutritional improvement occur in patients refractory to drug therapy without utilising complete bowel rest, then elemental diets might be preferable to TPN because the former are associated with fewer complications and are less expensive.

The present study was therefore designed to distinguish the beneficial effects of nutritional support and bowel rest as independent variables in the management of hospitalised patients with active Crohn's disease unresponsive to conventional drug treatment and in whom intestinal resection was considered the only other therapeutic alternative. This was undertaken by randomly and prospectively assigning patients to one of three groups: TPN and nil per os (NPO) where full nutritional support and bowel rest was enforced, defined formula diet (DFD) which provided only limited bowel rest, and partial parenteral nutrition and oral feeding (PPN) which acted as a control group where nutrition was maintained in the absence of bowel rest.

\section{Methods}

\section{PATIENTS}

Fifty one patients with Crohn's disease diagnosed by established radiological and/or endoscopic findings participated in the study. Each patient provided written informed consent and the study was independently approved by the Ethics Committee of each of the three participating institutions on or before 15 July, 1981. Entry into the trial was restricted to patients with severe Crohn's disease who had not responded to conventional medical management and where surgery might be considered a reasonable alternative form of treatment. Medical therapy before trial entry was generally provided as outpatients. Active Crohn's disease in the present study was defined as: a Crohn's disease activity index ${ }^{12}$ greater than 150 notwithstanding treatment with a prednisone dose of $15 \mathrm{mg} / \mathrm{d}$ or more in patients with small bowel involvement alone or combined with colonic disease, or treatment with sulphasalazine $3 \mathrm{~g} / \mathrm{d}$ and prednisone $15 \mathrm{mg} / \mathrm{d}$ or more in patients with Crohn's colitis for more than 4 weeks preceding the initiation of bowel rest therapy.

\section{EXPERIMENTAL DESIGN}

Patients were randomised into one of three nutritional support groups designed to be administered in hospital for 21 days, and this was controlled by an independent person not otherwise associated with the trial. Upon receiving patient information by telephone, assignment to the next available slot of an empty computer generated random table was pro- vided. Other participants in the trial were blind to the next available treatment group. The three nutritional groups included:

\section{TPN and NPO}

Patients were kept strictly NPO except for water taken with medications. Total parenteral nutrition was delivered through a subclavian vein catheter and each patient received $1 \mathrm{~g} / \mathrm{kg}$ ideal body weight (IBW) of protein as crystalline amino acids and 40 nonprotein $\mathrm{kcal} / \mathrm{kg}$ IBW per day. Thirty five per cent of non-protein kilocalories was given as a fat emulsion (10\% Intralipid) and the remainder as hypertonic dextrose. Electrolytes, minerals, and trace elements were provided in amounts needed to maintain normal serum concentrations. One ampoule of a standard vitamin preparation (MVI-12, USV) was given daily.

\section{Defined formula diet}

Patients received only a defined formula diet. Additional fluid and electrolyte requirements were met by administering $0.9 \%$ saline plus electrolytes through a peripheral intravenous infusion at the discretion of the individual physician. The defined formula diet (Precision-Isotonic*) was administered by nasogastric tube throughout the 24 hour period. The objectives of nutrient input in this group were to achieve an intake per 24 hours of $1 \mathrm{~g} / \mathrm{kg}$ IBW of protein and 40 non-protein IBW kcal $/ \mathrm{kg}$ with $35 \%$ of non-protein calories provided as fat.

\section{PPN plus oral diet}

Patients were encouraged to eat full palatable meals without restrictions on quantity or type. Because it was anticipated that patients in this group might fail to meet their daily protein and caloric requirements, partial protein/calorie supplementation (PPN) was provided at the onset through a peripheral vein or subclavian vein catheter and included $0.3 \mathrm{~g} / \mathrm{kg} \mathrm{IBW}$ of protein as crystalline amino acids and 15 nonprotein calories $/ \mathrm{kg}$ IBW equally divided between lipid and carbohydrate. Vitamins, electrolytes, minerals, and trace elements were also provided to meet individual patient requirements. This intravenous protein-calorie input was specifically chosen in anticipation that this less than ideal intravenous nutrition would suppress ketogenesis and avoid appetite suppression. From the onset a dietitian recorded on a daily basis the oral protein and caloric intakes of the patients.

All medications were discontinued with the excep-

*Precision-Isotonic contains $1 \mathrm{kcal} / \mathrm{cc}$ distributed (per $1000 \mathrm{cc}$ ) as $29 \mathrm{~g}$ egg albumin, 144 glucose oligosaccharides, and $30 \mathrm{~g}$ soy oil with an osmolality of $300 \mathrm{mosm} / 1$. 
tion of prednisone which was adjusted to, and maintained at, the nearest of one of three doses: 15 , 30 , or $45 \mathrm{mg} /$ day.

EVALUATION OF RESPONSE

Clinical, biochemical, radiological, endoscopic, and histological data were obtained before entry. The severity of the Crohn's disease was assessed by the Crohn's Disease Activity Index (CDAI) ${ }^{12}$ using a minor modification, as published previously. ${ }^{6}$ A score greater than 300 indicates severe disease activity, a score between 150 and 299 indicates moderate disease activity and a score less than 150 little or no activity. Patients were clinically monitored on a daily basis with a detailed CDAI, and a nutritional assessment recorded before entry and weekly throughout the investigational period.

A full clinical remission was considered to include a CDAI of less than 150 by the 21st day of therapy and the subsequent maintenance of a full oral diet without an increase in CDAI, medication or surgery. The trial was terminated if at least two physicians (attending physician and a physician who did not participate in primary care) independently concluded that one of the following criteria was met: (i) continuing the trial was hazardous for any reason; (ii) a progressive increase in CDAI to greater than 250 occurred by the end of the first week of therapy; (iii) there was no improvement in CDAI after two weeks of therapy; (iv) there was significant pain or vomiting over any three consecutive days; (v) the mean daily caloric intake after seven days did not achieve 1000 calories in the PPN group; (vi) the mean daily caloric input after seven days did not achieve 2000 calories in the DFD group.

All patients considered to have successfully undergone remission were discharged from hospital on prednisone which was tapered to a maintenance dose of $15 \mathrm{mg} /$ daily and were followed at one, three, six and 12 months. A relapse was considered to include: (i) a CDAI rising to greater than 250 ; (ii) complications requiring an increase in prednisone, TPN or surgery; (iii) other medical reasons (drug toxicity) that made continuing therapy hazardous.

\section{LABORATORY METHODS}

Haematocrit, blood glucose, serum electrolytes, creatinine, magnesium and albumin were measured in the routine haematological and biochemical laboratories using standardised automated techniques.

STATISTICAL ANALYSIS

All results are expressed as mean (SE). Significance of the differences in relapse rates was determined by life table analysis. Significance of differences
Table 1 Clinical parameters upon entry

\begin{tabular}{llll}
\hline & $T P N$ & $D F D$ & $P P N$ \\
\hline Age & $28 \cdot 8(17-59)$ & $31 \cdot 6(18-60)$ & $32 \cdot 4(21-54)$ \\
Sex & $10 \mathrm{~F} 7 \mathrm{M}$ & $8 \mathrm{~F} 11 \mathrm{M}$ & $8 \mathrm{~F} 7 \mathrm{M}$ \\
Disease duration & $92(17)$ & $66(17)$ & $67(19)$ \\
$\quad$ (months) & & & \\
Previous resections & 5 & 6 & 4 \\
Prednisone dose (mg) & $24(3)$ & $23(3)$ & $21(3)$ \\
Disease extent & & & \\
$\quad$ Small bowel +/- colon & 16 & 15 & 11 \\
$\quad$ Colon & 1 & 4 & 4 \\
Fistula & 5 & 3 & 3 \\
Inflammatory mass & 7 & 6 & 5 \\
Disease activity index & $369(92)$ & $298(26)$ & $370(32)$ \\
\hline
\end{tabular}

between the three groups for all other parameters was determined by ANOVA analysis between groups. When ANOVA was significant the differences between two groups was examined by the Newman-Keuls technique. A p value of 0.05 or less was considered significant.

\section{Results}

CLINICAL FEATURES OF THERAPEUTIC GROUPS Fifty one patients with active Crohn's disease, 26 women and 25 men, were admitted to the trial. Seventeen patients received TPN, 19 received a defined formula diet (DFD) and 15 patients were provided partial parenteral nutrition (PPN) and allowed unrestricted eating. The comparability of the groups is shown in Table 1. The DFD and PPN groups contained more patients with Crohn's colitis. Although there was some variation in the major complicating features within any one group, the number of patients with fistulous disease or inflammatory mass was similar among groups. The mean disease activity index, which indicated severe activity for each group, was also equivalent. The mean dose of prednisone upon entry did not differ among groups.

\section{OUTCOME DURING HOSPITAL ADMISSION Nutritional status}

At entry, the mean weight, triceps skin fold thickness and arm muscle circumference did not differ among the three groups (Table 2). After three weeks of therapy, none of these parameters showed any significant change when compared with baseline values. The oral intake by day 7 in patients receiving PPN tended to be higher in successful patients who consumed a mean $1970 \mathrm{kcal}$ (range: $1160-2950$ ) daily when compared with 1540 kcal (range: 400-2200) daily in patients who failed, although the difference was not significant. 
Table 2 Biochemical and anthropometric data at entry and after three weeks therapy

\begin{tabular}{|c|c|c|c|c|c|c|c|c|}
\hline \multirow[b]{2}{*}{ Group } & \multicolumn{2}{|c|}{$\begin{array}{l}\text { Weight } \\
(\mathrm{kg})\end{array}$} & \multicolumn{2}{|c|}{$\begin{array}{l}\text { Albumin } \\
(g / l)\end{array}$} & \multicolumn{2}{|c|}{$\begin{array}{l}\text { Arm Circumference } \\
(\mathrm{cm})\end{array}$} & \multicolumn{2}{|c|}{$\begin{array}{l}\text { Triceps Skinfold Thickness } \\
(\mathrm{cm})\end{array}$} \\
\hline & Entry & 3 weeks & Entry & 3 weeks & Entry & 3 weeks & Entry & 3 weeks \\
\hline TPN & $57(3)$ & $58(3)$ & $34(13)$ & $35(12)$ & $19.7(0.4)$ & $20 \cdot 5(0 \cdot 6)$ & $12.9(1 \cdot 8)$ & $12 \cdot 4(1 \cdot 4)$ \\
\hline DFD & $62(3)$ & $65(4)$ & $33(12)$ & $32(13)$ & $22.0(0.6)$ & $22.5(0.4)$ & $11 \cdot 6(2 \cdot 2)$ & $8 \cdot 8(1.9)$ \\
\hline PPN & $58(4)$ & $61(4)$ & $33(15)$ & $33(12)$ & $21.7(0.9)$ & $20 \cdot 8(0 \cdot 8)$ & $11 \cdot 7(1 \cdot 5)$ & $10 \cdot 8(1 \cdot 7)$ \\
\hline
\end{tabular}

Disease activity

As shown in the Figure, a significant $(p<0.01)$ fall in the mean activity index occurred in each group at the end of three weeks of therapy. There was no significant difference in the post-treatment activity index levels among groups.

\section{Remission upon discharge}

After three weeks of nutritional support, patients responding to therapy and tolerating a full oral diet without an increase in activity index were discharged on tapering doses of prednisone. As shown in

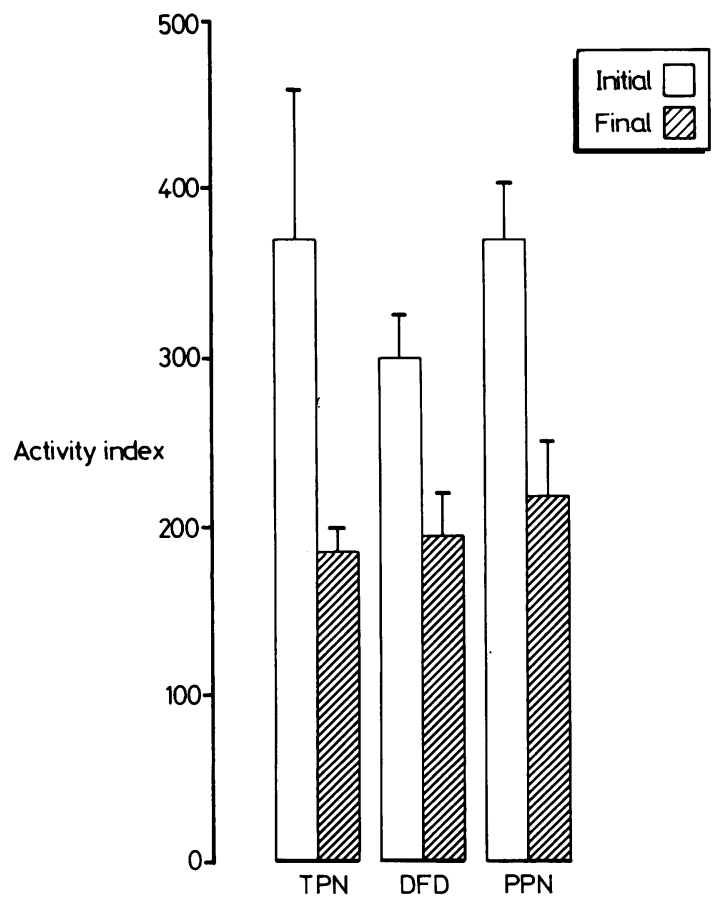

Fig. 1 Disease Activity Index in the three patient groups prior to and following nutritional therapy. TPN (total parenteral nutrition); $D F D$ (defined formula diet); $P P N$ (partial parenteral nutrition plus oral diet). Data presented as means $\pm S E$.
Table 3, remission rates at discharge were equivalent among the three groups: 12 patients responded to TPN, 11 patients to a DFD and nine patients to PPN and oral diet $\left(\chi^{2} 1.42\right.$ and $\left.1 \cdot 15 ; p=n / s\right)$.

\section{Treatment of failures}

All patients who failed in the TPN group required surgical management. Two of eight patients failing on a DFD required surgery for obstruction and abscess, respectively and a third patient with perianal disease ultimately responded to metronidazole; the other five patients were placed on either TPN alone (three patients) or TPN with an increased dose of corticosteroids (two patients) and all achieved a clinical remission. Three patients who failed on PPN required surgery for obstruction; the other three patients were placed on TPN and increased doses of corticosteroids, two of whom responded.

\section{OUTCOME UPON 12 MONTHS FOLLOW UP}

The outcome 12 months after discharge in patients responding to therapy and the timing of relapses is shown in Table 4 . The remission rates of $42 \%$ with TPN, 55\% with DFD and 56\% with PPN at 12 months were equivalent and not influenced by the type of nutritional support initially administered. Moreover, the provision of TPN (without increased corticosteroids) to patients who failed enteral nutritional support did not affect the outcome at one year. Of the three patient failures that remitted after being switched to TPN alone, two remained well at one year; therefore of the 15 patients ultimately responding to TPN, seven patients $(47 \%)$ maintained a remission for one year. Eight patients who relapsed within 12 months were treated surgically. Thus, of the 51 patients initially entered into the trial, 18 patients $(35 \%)$ required surgery, 17 patients $(34 \%)$ were treated medically for relapse and 16 patients $(31 \%)$ had a sustained remission.

\section{COMPLICATIONS}

None of the patients suffered any septic or metabolic complications that could be directly attributed to the type of nutrient therapy administered. 
Table 3 Response of patients to nutritional therapy

\begin{tabular}{llll}
\hline & $T P N$ & $D F D$ & $P P N$ \\
\hline Total on entry & 17 & 19 & 15 \\
Remission & $12(71 \%)$ & $11(58 \%)$ & $9(60 \%)$ \\
Failure & & $6(32 \%)$ & $3(20 \%)$ \\
$\quad$ Medical treatment & 0 & $2(10 \%)$ & $3(20 \%)$ \\
Surgery & $5(29 \%)$ & & \\
\hline
\end{tabular}

\section{Discussion}

The effect of nutritional support and/or bowel rest in patients with Crohn's disease has been subjected to controlled evaluation in only a limited number of clinical trials ${ }^{91314}$ and only one study included patients with small bowel involvement. Although the data suggest that bowel rest may not contribute to remission, none of these studies has addressed the question of whether nutritional support and/or bowel rest is of benefit in patients who have failed conventional medical treatment with drugs. The interest in this particular group arises because corticosteroids have proven efficacy in the management of patients with Crohn's disease ${ }^{12}$ and are much simpler and cheaper to deliver than complicated nutritional support systems. When drug therapy fails, however, the only alternative has been surgery. It is thus upon these patients that the present study has focused, as this is where the challenge to define new therapeutic avenues arises.

The results of this controlled trial indicate that nutritional support with or without bowel rest will facilitate remission in a majority of drug resistant patients with Crohn's disease. All three forms of nutritional therapy provided significantly indistinguishable reductions in disease activity and achieved equivalent outcomes. The mean dose of prednisone administered to each group was similar and did not influence these findings. Indeed, remission rates of $71 \%$ with TPN and $58 \%$ with DFD are remarkably comparable with mean figures reported in two recent reviews ${ }^{1516}$ that were derived from previous series of Crohn's patients treated either by TPN or by DFD. Of note, however, was the improvement in $60 \%$ of patients allowed to eat an oral diet. This latter observation accords well with the findings of Lochs $e t$ $a l,{ }^{9}$ and underscores the concept that bowel rest may not be an essential component for attaining remission. Furthermore, the present results indicate that, in the short term, nutritional support therapy appears to be an effective alternative to surgery given that all patients had previously received full drug treatment for at least four weeks before entry into the trial.

The design of the present study was specifically directed towards testing independently the role of bowel rest in contradistinction to nutritional support. Our data argue against bowel rest being a major factor contributing to an initial remission in patients with active Crohn's disease. The alternative possibility, however, namely whether there is a beneficial role for nutritional repletion, either through the enteral or the parenteral route, has also received little attention. Harries $\mathrm{et}^{\mathrm{al}{ }^{17}}$ in a controlled, crossover prospective study with malnourished Crohn's patients found significant clinical and biochemical improvement following the addition of an enteral non-elemental liquid supplement to an ordinary diet, although the nutritional factor(s) that might facilitate a remission were not defined and continue to remain speculative. Cell immunity is improved by nutritional repletion in patients with protein-calorie malnutrition $^{18}$ and could indirectly contribute to a reduction in disease activity. Alternatively, the provision of essential nutrients, such as glutamine, which influences the metabolism and differentiation of epithelial tissue $^{19}$ might enhance repair of diseased mucosa. Definition of the role of providing nutrition, per se, for patients with active Crohn's disease, using controlled trials remains an area for further investigation.

As implied from previous uncontrolled data, ${ }^{20}$ the present study confirms that an enteral defined formula diet was as efficacious as total parenteral nutrition in achieving remission in patients with active Crohn's disease. Enteral systems may therefore be preferable to TPN in the nutritional management of Crohn's patients given the simpler administration, at a lower $\operatorname{cost}^{21}$ and generally with fewer complications.

Two independent controlled trials have addressed

Table 4 Outcome of patients responding to nutritional therapy

\begin{tabular}{|c|c|c|c|c|c|c|c|}
\hline \multirow[b]{2}{*}{ Group } & \multirow[b]{2}{*}{ Total } & \multicolumn{2}{|l|}{$<3$ months } & \multicolumn{2}{|l|}{ 3-6 months } & \multicolumn{2}{|c|}{ 6-12 months } \\
\hline & & Remission & Relapse & Remission & Relapse & Remission & Relapse \\
\hline TPN & 12 & 11 & $1(1)^{*}$ & 8 & $3(1)$ & 5 & $3(1)$ \\
\hline DFD & 11 & 9 & $2(2)$ & 8 & $1(0)$ & 6 & $2(0)$ \\
\hline PPN & 9 & 8 & $1(1)$ & 8 & $0(0)$ & 5 & $3(2)$ \\
\hline
\end{tabular}

*Figures in parentheses indicate patients treated surgically. 
the role of total parenteral nutrition in Crohn's colitis. ${ }^{13{ }^{14}}$ Although the numbers of patients in each study were small, both concluded that in patients treated with corticosteroids, TPN and bowel rest failed to provide any advantage over an oral diet. Rather, TPN should be considered only as adjunctive treatment for supportive nutritional repletion. These findings when taken into consideration with the present study suggest that a positive clinical response from any nutritional support system is likely to occur in Crohn's patients with small bowel disease alone or where it is combined with large bowel disease. Several of our patients had complications of Crohn's disease including fistulae and inflammatory masses but the numbers were too small to draw any conclusions concerning responses in these specific subgroups.

Upon one year follow up about one half of patients in each nutritional group had relapsed. Moreover, this outcome was not affected by the subsequent provision of TPN to patients initially failing on DFD or PPN. These figures are substantially higher than the $18 \%$ relapse rate reported in one large retrospective series by Ostro $e t a^{6}$ of 100 Crohn's patients receiving TPN and complete bowel rest as primary therapy but more closely approximates the 54\% relapse rate observed by Bos $\mathrm{et}^{\mathrm{al}^{3}}$ who also studied retrospectively 86 Crohn's patients treated with TPN. Retrospective assessment as well as substantial variations in duration, extent and severity of disease may have affected the responses to nutritional therapy and contributed to these disparate results between various trials. In the present prospective study, all 51 patients could have undergone surgery as an acceptable therapeutic alternative; one year after nutritional support only 18 patients (35\%) required resection. Similarly, Muller $\mathrm{et} \mathrm{al}^{7}$ reported a $36 \%$ surgical resection rate after one year follow up in 25 patients that prospectively received TPN as the sole therapy for active Crohn's disease. These same investigators, however, noted that the cumulative relapse rate after four years in patients receiving TPN as primary therapy was four times higher than was observed from a retrospective analysis of patients undergoing surgical resection without previous TPN. Thus, a prospective evaluation to determine whether nutritional support achieves a longterm quality of life comparable to surgical resection alone is also required.

In summary, the present study shows that nutritional support without bowel rest will induce a clinical remission in the majority of patients with active Crohn's disease who have not responded to medical management. The outcome following defined formula diets is equivalent to treatment with total parenteral nutrition and thus DFD may be the preferred nutritional support modality given simpler administration, lower costs and fewer complications. Since a substantial relapse rate occurred upon one year follow up regardless of the nutritional system employed, a prospective evaluation of the efficacy of nutritional support modalities as primary therapy compared with surgical resection in drug resistant Crohn's patients needs to be undertaken.

This work was presented at the annual meeting of the American Gastroenterological Association, New York, 12-15 May, 1985 and has been published in abstract form (Gastroenterology 1985; 88: 140). The authors thank Mrs A Buffone for typing the manuscript.

\section{References}

1 Eisenberg HW, Turnbull RB, Jr, Weakley FL. Hyperalimentation as preparation for surgery in transmural colitis (Crohn's disease). Dis Colon Rectum 1974; 17: 469-75.

2 Reilly J, Ryan JA, Stole W, Fischer JE. Hyperalimentation in inflammatory bowel disease. Am J Surg 1976; 131: 192-200.

3 Bos LP, Weterman IT. Total parenteral nutrition in Crohn's disease. World J Surg 1980; 4: 163-66.

4 Greenberg GR, Jeejeebhoy KN. Total parenteral nutrition (TPN) in the primary management of Crohn's disease. In: Pena AS, Weterman IT, Booth CC, Strober $\mathrm{W}$, eds. Developments in gastroenterology: recent advances in Crohn's disease. The Hague: Martinus Nijoff Publishers, 1981: 492-98.

5 Elson CO, Layden TJ, Nemchausky BA, Rosenberg JL, Rosenberg IH. An evaluation of total parenteral nutrition in the management of inflammatory bowel disease. Dig Dis Sci 1980; 25: 42-48.

6 Ostro MJ, Greenberg GR, Jeejeebhoy KN. Total parenteral nutrition and complete bowel rest in the management of Crohn's disease. JPEN 1985; 9: 280-87.

7 Muller JM, Keller HW, Erasmi H, Pichlmaier H. Total parenteral nutrition as the sole therapy in Crohn's disease - a prospective study. Br J Surg 1983; 70: 40-43.

8 Greenberg GR, Jeejeebhoy KN. Intravenous proteinsparing therapy in patients with gastrointestinal disease. JPEN 1979; 3: 427-32.

9 Lochs H, Meryn S, Marosi L, Ferenci P, Hortnag H. Has total bowel rest a beneficial effect in the treatment of Crohn's disease? Clin Nutr 1983; 2: 61-64.

10 O'Morain C, Segal AW, Levi AJ. Elemental diets as primary treatment of acute Crohn's disease: a controlled trial. Br Med J 1984; 288: 1859-62.

11 Saverymuttu S, Hodgson HJF, Chadwick VS. Controlled trial comparing prednisone with an elemental diet plus non-absorbable antibiotics in active Crohn's disease. Gut 1985; 26: 994-98.

12 Summers RW, Switz DM, Sessions JT, et al. National cooperative Crohn's disease study. Results of drug treatment. Gastroenterology 1979; 77: 827-28.

13 Dickenson RJ, Ashton MR, Axon ATR, Smith RC, 
Yeung CK, Hill GL. Controlled trial of intravenous hyperalimentation and total bowel rest as an adjunct to the routine therapy of acute colitis. Gastroenterology 1980; 79: 1199-204.

14 McIntyre PB, Powell-Tuck J, Wood SR, et al. Controlled trial of bowel rest in the treatment of severe acute colitis. Gut 1986; 27: 481-84.

15 Driscoll RH, Jr, and Rosenberg IH. Total parenteral nutrition in inflammatory bowel disease. Med Clin $N$ Am 1978; 62: 185-201.

16 Greenberg GR. Inflammatory bowel disease. In: Kinney JM, Jeejeebhoy KN, Hill GL, Owen OE, eds. Nutrition and-metabolism in patient care. Philadelphia: WB Saunders, 1988: 266-80.

17 Harries AD, Danis V, Heatley RV, Jones LA, Fifield R and Newcombe RG. Controlled trial of supplemental oral nutrition in Crohn's disease. Lancet 1983; i: 887-90.

18 Chandra R. Rosette-forming T lymphocytes and cellmediated immunity in malnutrition. $\mathrm{Br}$ Med J 1974; iii: 608-9.

19 Spector MH, Traylor J, Young EA, Wiser E. Stimulator of mucosal growth by gastric and ileal infusion of single amino acids in parenterally nourished rats. Digestion 1981; 21: 33-40.

20 Lochs H, Egger-Schodle M, Schuh R, Meryn ST, Westphal G, Potzi R, and Rhodes J. Is tube feeding with elemental diets a primary therapy of Crohn's disease? Klin Wochenschr 1984; 62: 821-25.

21 Koretz RL. Nutritional support: how much for how much? Gut 1986; 27 : 85-89. 